\title{
Blockade of Transforming Growth Factor- $\beta 1$ Accelerates Lymphatic Regeneration during Wound Repair
}

\author{
Tomer Avraham, ${ }^{\star}$ Sanjay Daluvoy, ${ }^{*}$ \\ Jaime Zampell, ${ }^{*}$ Alan Yan, ${ }^{*}$ Yosef S. Haviv, ${ }^{\dagger}$ \\ Stanley G. Rockson, ${ }^{\star}$ and Babak J. Mehrara* \\ From the Division of Plastic and Reconstructive Surgery," \\ Department of Surgery, Memorial Sloan-Kettering Cancer Center, \\ New York, New York; the Department of Medicine, ${ }^{\dagger}$ Hadassah- \\ Hebrew University Medical Center, Jerusalem, Israel; and the \\ Division of Cardiology, Department of Medicine, Stanford \\ University Medical Center, Stanford, California
}

Lymphedema is a complication of cancer treatment occurring in approximately $50 \%$ of patients who undergo lymph node resection. Despite its prevalence, the etiology of this disorder remains unknown. In this study, we determined the effect of soft tissue fibrosis on lymphatic function and the role of transforming growth factor (TGF)- $\beta 1$ in the regulation of this response. We determined TGF- $\beta$ expression patterns in matched biopsy specimens collected from lymphedematous and normal limbs of patients with secondary lymphedema. To determine the role of TGF- $\beta$ in regulating tissue fibrosis, we used a mouse model of lymphedema and inhibited TGF- $\beta$ function either systemically with a monoclonal antibody or locally by using a soluble, defective TGF- $\beta$ receptor. Lymphedematous tissue demonstrated a nearly threefold increase in the number of cells that stained for TGF- $\beta 1$. TGF- $\beta$ inhibition markedly decreased tissue fibrosis, increased lymphangiogenesis, and improved lymphatic function compared with controls. In addition, inhibition of TGF- $\beta$ not only decreased TGF- $\beta$ expression in lymphedematous tissues, but also diminished inflammation, migration of T-helper type 2 (Th2) cells, and expression of profibrotic Th2 cytokines. Similarly, systemic depletion of T-cells markedly decreased TGF- $\beta$ expression in tail tissues. Inhibition of TGF- $\beta$ function promoted lymphatic regeneration, decreased tissue fibrosis, decreased chronic inflammation and Th2 cell migration, and improved lymphatic function. The use of these strategies may represent a novel means of preventing lymphedema after lymph node resection. (Am J Pathol 2010, 177:3202-3214; DOI: 10.2353/ajpath.2010.100594)

Lymphedema is a dreaded complication of cancer management that results from the disruption of Iymphatic channels. It is estimated that 3 to 5 million Americans have chronic lymphedema and suffer from chronic swelling, recurrent infections, pain, impaired function, and decreased quality of life. ${ }^{1-4}$ Remarkably, despite the prevalence and morbidity of lymphedema, there is currently no known cure and treatment remains primarily symptomatic in nature with the goal of preventing disease progression. Patients are required to wear tight, uncomfortable garments for the rest of their lives and risk worsening of the condition with repeated infections. ${ }^{5}$

The development of effective treatment options for lymphedema has been hampered by the fact that the etiology of this disorder remains poorly understood. Thus, although it is clear that the initiating event in postsurgical lymphedema is injury to the lymphatic channels, it is unknown why some patients develop this complication while others who are identically treated do not. In addition, it remains unknown why lymphedema develops in some patients after seemingly trivial lymphatic injury. ${ }^{6}$ Similarly, although large studies have identified critical risk factors for the development of lymphedema such as radiation, infections, and obesity, it is unknown how

Supported in part by the Plastic Surgery Educational Foundation (B.J.M.). T.A. was funded in part by a fellowship grant from the Plastic Surgery Educational Foundation. J.Z. was supported by T32 Surgical Oncology Training grant NIH T32 CA 009501. Technical services provided by the Memorial Sloan-Kettering Cancer Center Small-Animal Imaging Core Facility, supported in part by NIH Small-Animal Imaging Research Program grant number R24 CA83084 and NIH Center grant number P30 CA08748, are gratefully acknowledged.

Accepted for publication August 3, 2010

None of the authors have any commercial associations or financial relationships that would create a conflict of interest with the work presented in this article.

Address reprint requests to Babak J. Mehrara, M.D., FACS, 1275 York Ave, Room MRI 1005, New York, NY 10065. E-mail: mehrarab@mskcc.org. 
these factors contribute to the pathophysiology of lymphedema. ${ }^{7-9}$

Recent studies have demonstrated that fibrosis plays a role in the pathogenesis of lymphedema. For example, we have shown that fibrosis markedly delays lymphatic regeneration and impairs lymphatic function during wound repair. ${ }^{10,11}$ More recently, we have found that radiation induced tissue fibrosis significantly impairs lymphatic function. ${ }^{12}$ This concept is supported by the fact that the composition of the extracellular matrix (ECM) is a critical regulator of hydraulic conductivity of the skin and an important regulator of interstitial fluid (lymphatic) flow. ${ }^{13,14}$ The interaction between tissue conductivity and interstitial fluid flow is likely regulated, at least in part, by anchoring filaments that serve as a sensing mechanism for interstitial fluid accumulation. ${ }^{15}$ Therefore, the loss of compliance of soft-tissues and lymphatics as is observed in histological samples obtained from patients with chronic lymphedema can markedly decrease lymphatic function leading to obliteration of lymphatic vessels.

The cellular mechanisms that regulate tissue fibrosis have been investigated in a number of models. Remarkably, despite the marked variability in organ systems and inciting events that have been studied, the mechanisms that promote tissue fibrosis and replacement of functioning parenchyma with scar appear to be conserved. ${ }^{16}$ These studies have demonstrated critical roles for chronic inflammatory reactions in response to repeated injury or persistent irritants leading to differentiation of T-helper cells along the T-helper 2 (Th2) lineage with resultant expression of profibrotic cytokines including interleukin (IL)-4, IL-13, and transforming growth factor (TGF)- $\beta 1 .{ }^{17-21}$ These cytokines then act in concert to promote the expression and inhibit degradation of extracellular matrix products leading to tissue fibrosis.

TGF- $\beta 1$ is a well recognized regulator of extracellular matrix synthesis. ${ }^{22}$ Loss of TGF- $\beta 1$ signaling either in knockout animals (eg, SMAD3 knockouts) or through the use of small molecule inhibitors decreases skin fibrosis resulting from radiation therapy. ${ }^{23,24}$ In fact, abrogation of TGF- $\beta 1$ function decreases fibrosis in virtually every organ system including lung, liver, kidney, skin, and cornea. ${ }^{25-43}$ Th2 cytokines interact and cooperate with TGF- $\beta 1$ in the regulation of tissue fibrosis. ${ }^{44}$ In addition to its profibrotic effects, TGF- $\beta 1$ inhibits lymphatic endothelial cell proliferation, migration, and tubule formation. ${ }^{11,45}$ These features have led us to hypothesize that increased expression of TGF- $\beta 1$ as a result of lymphatic fluid stasis impairs lymphatic function by promoting tissue fibrosis and by directly inhibiting lymphangiogenesis.

The purpose of this study was to determine the role of TGF- $\beta 1$ and its interactions with Th2 cytokines on the regulation of lymphatic repair and tissue fibrosis in response to lymphatic fluid stasis. We demonstrate that TGF- $\beta 1$ expression is increased in the lymphedematous limbs of patients as compared with matched biopsy specimens from their unaffected extremity. Using a mouse tail model, we demonstrate that systemic or local inhibition of TGF- $\beta 1$ markedly improves lymphangiogenesis during wound repair, is associated with decreased expression of IL-4 and IL-13, and significantly decreases chronic inflammation and tissue fibrosis. Similarly, we show that antibody depletion of $\mathrm{CD}^{+}$cells results in significantly decreased TGF- $\beta 1$ expression and tissue fibrosis indicating interaction between chronic T-cell inflammatory responses and TGF- $\beta 1$ expression. Taken together these findings demonstrate that TGF- $\beta 1$ plays an important role in the regulation of tissue fibrosis in response to lymphedema and that this effect is associated with a chronic T-cell inflammatory reaction and elaboration of IL-4 and IL-13.

\section{Materials and Methods}

\section{Human Lymphedema Tissue Analysis}

Patients with chronic postsurgical lymphedema were identified at the Stanford Center for Lymphatic and Venous Disorders $(n=7)$. After informed consent, full thickness $5-\mathrm{mm}$ skin punch biopsies were obtained from the patient's lymphedematous limb by using standard sterile technique. Control biopsies were obtained from the identical location from the contra-lateral nonlymphedematous limb. These studies were approved by the Institutional Review Board of Stanford University. Immunohistochemical analysis was performed by using anti-TGF- $\beta 1$ antibody (Santa Cruz Antibodies, Santa Cruz, CA), and sections were imaged by using the Mirax Slide Scanner (Carl Zeiss Microimaging, Munich, Germany) as described below.

\section{Mouse Tail Model of Lymphedema}

To study the effects TGF- $\beta 1$ on tissue changes resulting from sustained lymphatic fluid stasis, we modified a well described mouse tail model in 10- to 12-week-old female C57/BL6 mice (Jackson Labs, Bar Harbor, ME). Briefly, a 2-mm wide circumferential full thickness skin excision was performed $20 \mathrm{~mm}$ from the mouse tail to remove the superficial lymphatics, and the deep lymphatics were ligated by using a surgical microscope (StereoZoom SZ-4; Leica, Wetzlar, Germany). ${ }^{10,11}$ The wound was then dressed with an occlusive dressing to prevent wound desiccation and contamination. It is important to note that this model differs from the mouse tail model of lymphatic regeneration described by Swartz and colleague ${ }^{46}$ because the wounds are not covered with a collagen matrix. The lack of collagen gel matrix delays lymphatic regeneration resulting in tail edema for a minimum of 9 to 10 weeks. All animal procedures were approved by the Resource Animal Research Center Institutional Animal Care and Usage Committee at Memorial Sloan-Kettering Cancer Center (New York, NY).

\section{Modulation of Local TGF- $\beta 1$ Activity}

To systemically inhibit TGF- $\beta 1$ function, experimental $(n=8)$ mice underwent tail excision as described above and were treated with a monoclonal antibody against mouse TGF- $\beta$ (TGFmab; $5 \mathrm{mg} / \mathrm{kg}$ diluted in $150 \mu \mathrm{l}$ of PBS, intraperitoneally), clone 1D11 (Bio-x-cell, West Lebanon, 
$\mathrm{NH})$. Using this treatment protocol, this antibody has been used in a variety of studies and has been shown to be effective in blocking signaling in vivo of all TGF- $\beta$ isoforms. ${ }^{47}$ TGFmab treatment was initiated 24 hours before tail surgery and then three times per week for 6 weeks. Control animals $(n=8)$ were treated with a similar dose of isotype control monoclonal antibody also administered intraperitoneally.

To evaluate the impact of local TGF- $\beta 1$ blockade on lymphatic regeneration, animals underwent tail excision and the wounds were covered with $1 \%$ rat tail collagen $\left(\mathrm{BD}\right.$ Biosciences, San Jose, CA) containing $1 \times 10^{9}$ plaque forming units of a recombinant adenovirus expressing a soluble dominant negative TGF- $\beta$ type II receptor (Ad-DN-RII) capable of binding all TGF- $\beta$ isoforms but incapable of initiating intracellular signaling. ${ }^{48}$ The transgene in this construct is expressed under the control of the constitutively active cytomegalovirus and overexpression and secretion of the defective receptor by transfected cells competes with endogenous TGF- $\beta$ RII thereby acting in a dominant negative manner to suppress TGF- $\beta$ function. The collagen gel was used in this portion of the study as a delivery vehicle because preliminary studies using other delivery methods failed to promote high level tissue transfection. Adenovirus was not used systemically in these experiments as adenoviruses tend to home to the lung and liver, and as such are likely to produce unwanted systemic side effects. Control animals underwent similar tail excision and the wound was covered either with $1 \%$ rat tail collagen containing PBS or $1 \times 10^{9}$ plaque forming units of a recombinant adenovirus expressing the bacterial LacZ protein under the regulation of a cytomegalovirus promoter (Ad-Lac-Z). Additional control animals were treated with $1 \%$ collagen gel containing $50 \mathrm{ng}$ of recombinant human TGF- $\beta 1$ (R\&D Biosciences, San Jose, CA). Animals ( $n=6$ to 8 ) were evaluated for 6 weeks and sacrificed for analysis.

\section{Depletion of $\mathrm{CD}^{+}$Cells}

To deplete $\mathrm{CD}^{+} \mathrm{T}$ cells, experimental $(n=8)$ mice were treated with a monoclonal antibody against mouse CD3e (CD3mab; $20 \mathrm{mg} / \mathrm{kg}$ diluted in $150 \mu \mathrm{l}$ of PBS, intraperitoneally), clone 145-2C11 (Bio-x-cell) beginning 5 days before surgery and every 5 days for 6 weeks following tail excision as described above. This protocol has been previously shown to result in effective T-cell depletion with minimal toxicity. ${ }^{49}$ Control animals $(n=8)$ were treated with a similar dose of isotype control monoclonal antibody also administered intraperitoneally. Efficiency of depletion was evaluated by using flow cytometry of single cell splenic suspensions.

\section{Lymphoscintigraphy}

To quantify lymphatic transport ${ }^{99} \mathrm{mTc}$-sulfur colloid (100 $\mathrm{nm}$ particle size; 400 to $800 \mu \mathrm{Ci}$ in $\sim 50 \mu \mathrm{l}$ ) was injected intradermally $20 \mathrm{~mm}$ from the tail tip. Dynamic planar gamma camera images were acquired in 15- to 600second frames for up to 2.5 hours after injection by using an X-SPECT (Gamma Medica, Northridge, CA) fitted with low-energy parallel-hole collimators. Resulting dynamic images were analyzed by using ASIPro (CTI Molecular Imaging, Knoxville, TN), and region-of-interest analysis was performed to derive the decay adjusted activity. Time-activity data were then fit to a flat line, a function exponentially decreasing to an asymptotic value for the injection site, or a function exponentially increasing to an asymptotic value for the individual lymph nodes.

\section{Tail Volume Determination and Microlymphangiography}

Changes in tail volumes were measured by blinded reviewers at various time points by using the truncated cone formula by measuring the circumference of the tail at $10-\mathrm{mm}$ intervals starting at the distal margin of the tail excision using a digital caliper. ${ }^{50} \mathrm{~A}$ minimum of four to five animals were evaluated in each group/time point. Microlymphangiography was performed in the same animals before sacrifice to evaluate the gross structure of the capillary lymphatics as previously described. ${ }^{51}$ Briefly, $15 \mu \mathrm{l}$ of a $10 \mathrm{mg} / \mathrm{ml}$ solution of $2000 \mathrm{kDa}$ dextran conjugated to a fluorescein isothiocyanate molecule was injected approximately $10 \mathrm{~mm}$ proximal to the tip of the mouse tail under constant pressure. This molecule is too large to enter blood vessels but can enter lymphatics, which are designed to transport large molecules in the interstitial fluid. Capillary lymphatics were then visualized in the tail by using the Leica MZFL3 Stereoscope (Wetzlar, Germany). Bright-field and fluorescent images were obtained at consistent exposure, gain, and magnification and overlaid by using Volocity software (PerkinElmer, Waltham, MA).

\section{Specimen Preparation, Histology, and Immunohistochemical Staining}

Ten-millimeter tail sections centered on the repair site were harvested, fixed in $4 \%$ paraformaldehyde, decalcified in Immunocal (Decal Chemical Corporation, Tallman, NY), and embedded in paraffin. Five-micrometer longitudinal and cross-sectional histology sections were prepared and stained by using hematoxylin and eosin or Van Giessen stains using standard techniques and visualized by using the Mirax Slide Scanner (Carl Zeiss Microimaging). Dermal thickness was determined by using the Mirax Viewer software (Carl Zeiss Microimaging). Briefly, a distance of $4 \mathrm{~mm}$ was measured distal to the wound edge in standardized longitudinal histological sections, and the dermal thickness was measured from the dermal/ epidermal junction to the deep muscles. A minimum of two measurements were made per animal per group by two blinded reviewers.

Sirius red (Direct Red 80; Sigma, St. Louis, MO) staining was performed to evaluate the degree of fibrosis in the specimens as previously described. ${ }^{52}$ Birefringence pattern and hue were evaluated by using polarized light microscopy to determine collagen density, pattern of 
deposition, and maturity. This analysis is based on the fact that normal tissues display fine collagen bundles with a green/yellow birefringence arranged in a random pattern, whereas soft tissue fibrosis results in formation of thicker bundles of collagen demonstrating orange-red birefringence and deposited in parallel bundles. ${ }^{53}$ The scar index is a quantitative analysis of fibrosis and is calculated by comparing the ratio of orange/red to yellow/green staining using Metamorph Offline software (Molecular Devices Corporation, Sunnyvale, $C A$ ) in a minimum of three sections per animal ( $n=3$ to 5 animals per time point).

Immunohistochemical staining was performed as previously described. ${ }^{54}$ Lymphatic vessels were identified by using podoplanin (Abcam, Cambridge, MA). Other antibodies used were CD-45 (pan-leukocyte antigen; R\&D Systems, Minneapolis, MN), CD4 antibody, F480 (macrophages), pSmad3, interferon (IFN)- $\gamma$, IL-13 (all from Abcam), and $\beta$-galactosidase (Biogenesis, Poole, United Kingdom). Secondary antibody was from VECTASTAIN ABC Kit (Vector, Burlingame, CA) and developed by using diaminobenzidine. Negative control sections were incubated with secondary antibody only. Bright field images were obtained by using a Leica TCS microscope. Double immunostaining was visualized by using Nuance Multispectral imaging System (LOT Oriel Group, Daimstadt, Germany), followed by spectral separation for fluorescent visualization. Specificity was confirmed by using single stained sections and negative controls. Cell counts were performed in three to five high powered fields per animal ( $n=3$ to 5/time point) by two blinded reviewers. $\beta$-galactosidase activity was assessed in Ad-Lac-Z transfected tails 1 week after transfection by using the $\beta$-gal staining kit (Invitrogen, Carlsbad, CA) according to the manufacturer's protocol.

\section{Western Blot Analysis}

Skin and subcutaneous tissue were isolated from the tail soft tissues $5 \mathrm{~mm}$ distal to the wound. Total cellular protein was isolated by using the Qiagen DNA/RNA/ Protein mini kit using the manufacturer's protocol (Qiagen, Valencia, CA) and quantified by using the Bradford method. Western blotting was performed as previously described for CD45, CD4, IL-4, IFN- $\gamma$, IL-2, IL-13, TBet, Gata-3, and TGF- $\beta 1$, vascular endothelial growth factor (VEGF)-C, VEGF-A, and hepatocyte growth factor (all from Abcam except for TGF- $\beta 1$, which was from Santa Cruz Biotechnology). ${ }^{11}$ Equal loading was confirmed by using Actin or tubulin antibody (Abcam). For relative expression analysis, $\mathrm{NIH}$ Image $\mathrm{J}$ software was used to determine band intensity. Intensity was corrected for tubulin loading for that particular blot to ensure appropriate comparisons. Immunoreactivity was determined by using the Enhanced Chemiluminescence $(E C L)$ chemiluminescence detection system (Amersham, Arlington Heights, IL).

\section{Statistical Analysis}

Multigroup comparison with similar variance was performed by using one-way analysis of variance with the
A
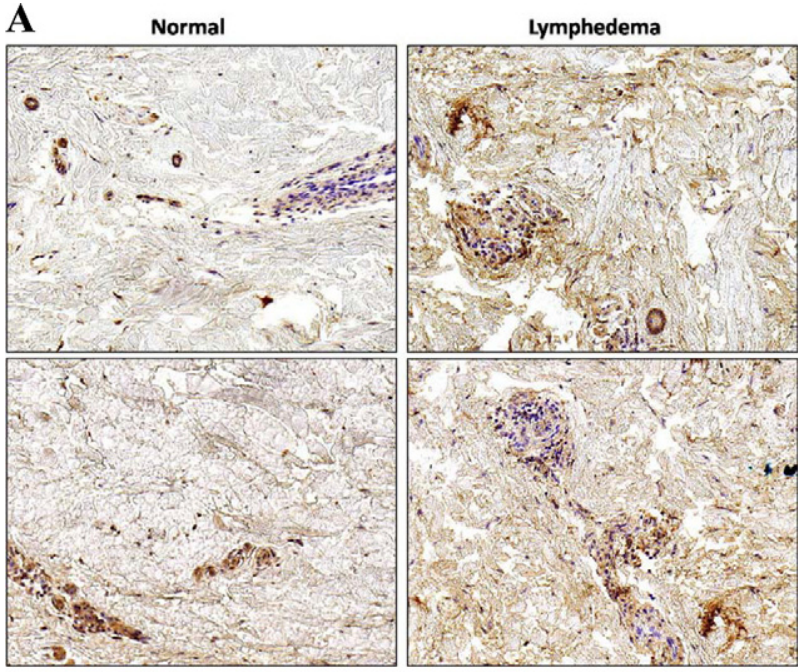

B

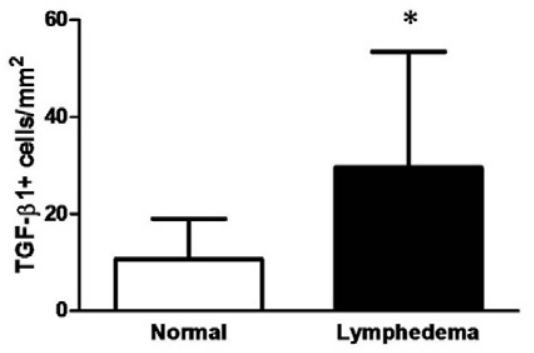

$\mathbf{C}$

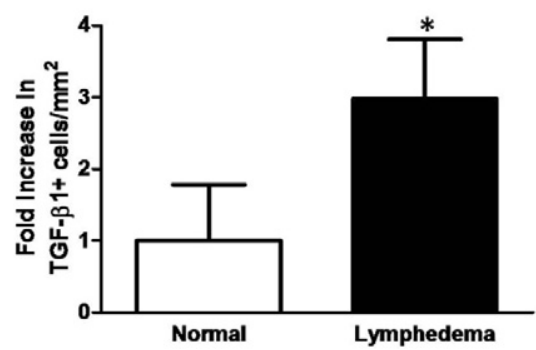

Figure 1. Lymphedema is associated with increased expression of TGF- $\beta 1$ A: Immunohistochemical analysis of matched skin biopsy specimens from lymphedematous and normal limbs of patients demonstrates increased intracellular and extracellular staining for TGF- $\beta 1$ in lymphomatous tissues Representative figures from two patients are shown at $40 \times$ magnification. B Number of TGF- $\beta 1^{+}$cells/High Power Field in lymphomatous and normal tissues (mean $\pm \mathrm{SD} ;{ }^{*} P<0.04$ ). C: Fold change in number of TGF- $\beta 1^{+}$ cells/HPF in lymphedematous versus normal limbs (mean $\pm \mathrm{SD} ;{ }^{*} P<0.02$ ).

Tukey-Kramer posthoc test. Student's t-test was used for analyzing differences between two groups. A minimum of five animals was used in each experimental group. Data are presented as mean \pm SD unless otherwise noted with $P<0.05$ considered significant.

\section{Results}

\section{Lymphedema Is Associated with Increased Local Expression of TGF- $\beta 1$}

Immunohistochemical localization of TGF- $\beta 1$ was performed in matched skin biopsy specimens from lymphedematous and normal contra-lateral limb (Figure 1, A-C). Biopsy specimens from lymphedematous limbs demon- 
A

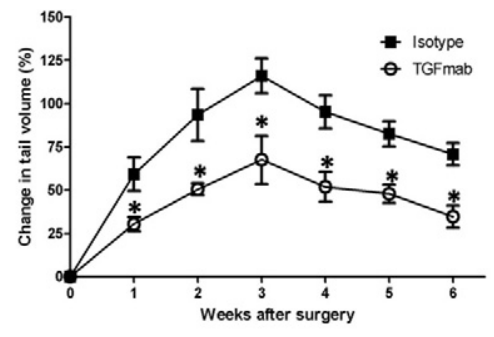

C

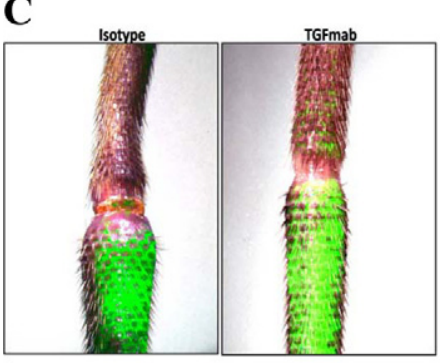

D

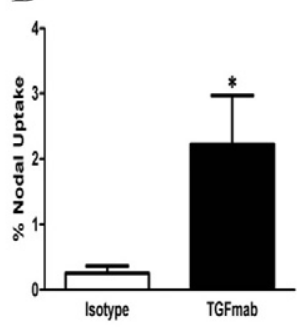

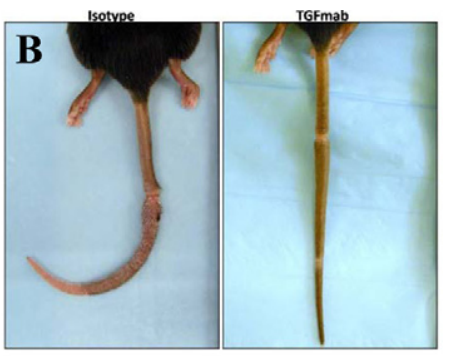

Isotype
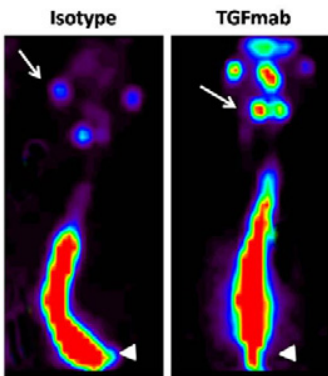

F

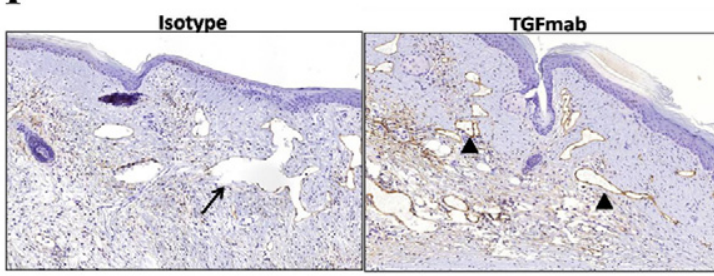

H

G

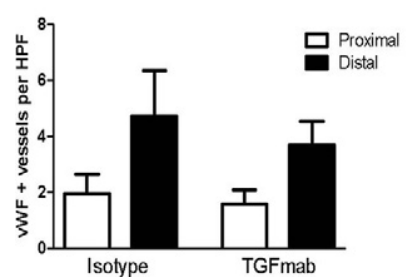

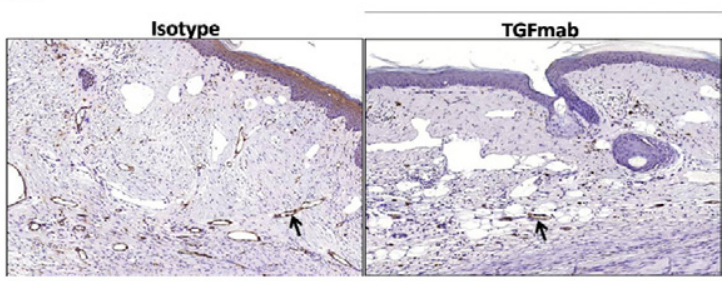

Figure 2. Systemic TGF- $\beta 1$ blockade decreases tail lymphedema and improves lymphatic regeneration. A: Tail volume measurements in isotype control and TGFmab-treated animals (mean \pm SEM; $\left.{ }^{*} P<0.05\right)$. B: Representative photographs of isotype- (left) and TGFmab (right)-treated animals. Note improved wound repair, minimal edema, and lack of tail curvature indicative of fibrosis in TGFmab-treated animals as compared with controls. C: Representative microlymphangiography demonstrates flow of fluorescenttagged large molecular weight dextran across the wound only in the TGFmab-treated animals. In contrast, isotype controls demonstrate pooling of fluorescence distal to the wound. D: Tc ${ }^{99}$ lymphoscintigraphy demonstrating nearly ninefold greater lymphatic transport to lymph nodes at the base of the tail in TGFmab-treated mice as compared with isotype control (mean $\pm \mathrm{SEM} ;{ }^{*} P<0.0001$ ). Representative lymphoscintographs are presented (arrowhead: injection site near tip of tail; arrow: lymph node). E and F: Quantitation of podoplanin-positive lymphatic vessels demonstrates nearly twofold increase in number of vessels in tail tissues located distal to the zone of lymphatic disruption in mice treated with TGFmab as compared with isotype controls (mean $\pm \mathrm{SD} ; P<0.0001$ ). Representative $20 \times$ micrographs demonstrating scarce and dilated podoplanin positive vessels (arrow) in isotype-treated mice and abundant collapsed lymphatics (arrowheads) in TGFmab-treated mice. G and $\mathbf{H}$ : Quantitation of VWF-positive blood vessels (arrows), demonstrates a nonsignificant trend toward lower numbers of blood vessels in the TGFmab-treated animals. strated a nearly threefold increase in the number of TGF- $\beta 1$ positive cells as compared with specimens obtained from the normal limb $(P<0.05)$. In addition, two blinded reviewers consistently noted markedly more interstitial staining for TGF- $\beta 1$ in the papillary and reticular dermis of lymphedematous skin samples for TGF- $\beta 1$ when matched tissue sections were analyzed side-by-side.

\section{Systemic TGF- $\beta 1$ Blockade Improves Lymphatic Function and Decreases Tissue Fibrosis}

Treatment with systemic TGFmab was well tolerated with no evidence of toxicity or wound healing complications. Serial measurement of tail volumes demonstrated that animals treated with TGFmab had significantly less tail lymphedema as determined by percent change from baseline tail volumes compared with isotype control starting at 1 week following surgery and persisting in weekly measurements for 6 weeks (Figure 2A). On average, TGFmab treated animals had a $50 \%$ to $60 \%$ decrease in their tail volumes as compared with isotype control treated mice $(P<0.001$; Figure $2 \mathrm{~A})$. These changes in tail volume were grossly apparent at the 6-week time point with isotype treated animals demonstrating significant lymphedema, fibrosis, and tail contracture resulting in a fixed curved appearance of the tail (Figure 2B). In contrast, TGFmab treated animals had significantly less edema and a more normal appearing, supple tail with no evidence of fibrosis or contracture.

Decreased tail lymphedema in TGFmab treated animals was associated with markedly improved lymphatic transport as assessed by microlymphangiography demonstrating transport of a fluorescein isothiocyanate-labeled high molecular weight dextran molecule across the tail excision site (Figure 2C). In contrast, isotype treated animals demonstrated pooling of the fluorescein isothiocyanate-labeled molecule distal to the site of tail excision. This finding was confirmed by lymphoscintigraphy demonstrating a nearly ninefold greater uptake of Tc-99 labeled sulfur colloid by the lymph nodes at the base of the tail 2 hours following intradermal injection near the tip of the tail $(P<0.0001$; Figure 2D). 
Consistent with the known anti-lymphangiogenic properties of TGF- $\beta 1$, improved lymphatic function in TGFmab treated animals was associated with augmented lymphatic regeneration. Tail sections from TGFmab treated animals had a nearly fivefold increase in the number of podoplanin positive lymphatic vessels as compared with isotype treated controls $(P<0.0001$; Figure $2 \mathrm{E})$. In addition, consistent with improved lymphatic function observed in our microlymphangiography and lymphoscintigraphy analyses, we noted the presence of collapsed lymphatics in TGFmab treated animals and abnormally dilated, ectatic lymphatics in isotype controls (Figure 2F). TGFmab treatment resulted in a moderate, though not statistically significant, decrease in the number of microvascular blood vessels (Figure 2, $\mathrm{G}$ and $\mathrm{H}$ ).

Soft tissue fibrosis is a pathological hallmark of lymphedema. As such we investigated the impact of systemic TGF- $\beta$ blockade with TGFmab on fibrosis. H\&E stained tail sections demonstrated markedly decreased dermal fibrosis and thickening in TGFmab treated animals as compared with isotype controls (Figure 3A). Consistent with our gross observations, TGFmab treated animals had evidence of mild edema and dermal thickening in the distal portions of the tail that was approximately $50 \%$ greater than normal mouse tail skin (Figure 3B). In contrast, isotype treated animals had a nearly twofold increase in dermal thickness $(P<0.0001)$. These findings were reflected in a significant decrease (nearly twofold) in soft tissue scarring in TGFmab treated animals as assessed using Sirius red staining (Figure 3C; $P<$ 0.0052). TGFmab treated animals had a predominately yellow-green birefringence pattern of randomly arranged collagen fibers staining consistent with decreased scarring, whereas isotype treated animals had significant accumulation of parallel arranged, predominantly red-orange fibers consistent with more severe fibrosis.

\section{Systemic TGF- $\beta 1$ Blockade Reduces Lymphedema Induced Chronic Inflammation}

Lymphedema is clinically associated with chronic mononuclear inflammation. Consistent with this fact we found that isotype treated animals had a significant infiltration of CD45 positive leukocytes in the lymphedematous portion of the tail. In addition, leukocyte infiltration followed gradients of lymphatic stasis with nearly threefold increase in the number of inflammatory cells located distal to the site of lymphatic occlusion (Figure 4A; $P<0.001$ comparing proximal to distal). This finding demonstrates that the changes in inflammatory cell infiltration are due to lymphatic fluid stasis and do not merely reflect changes in wound healing. Treatment with TGFmab resulted in a significant decrease in overall inflammation $(P<0.001)$. This effect was most notable in the distal (ie, lymphedematous) portion of the tail resulting in a nearly threefold decrease in the number of $\mathrm{CD}_{4} 5^{+}$leukocytes. We have previously found that the nearly $70 \%$ of $\mathrm{CD} 45^{+}$leukocytes in lymphedematous tissues are also $\mathrm{CD}^{+}$positive (T. Avraham, unpublished data). Similarly, in the current study we found a large number of $\mathrm{CD}^{+}$cells in the lymphedematous portion of the tail
A
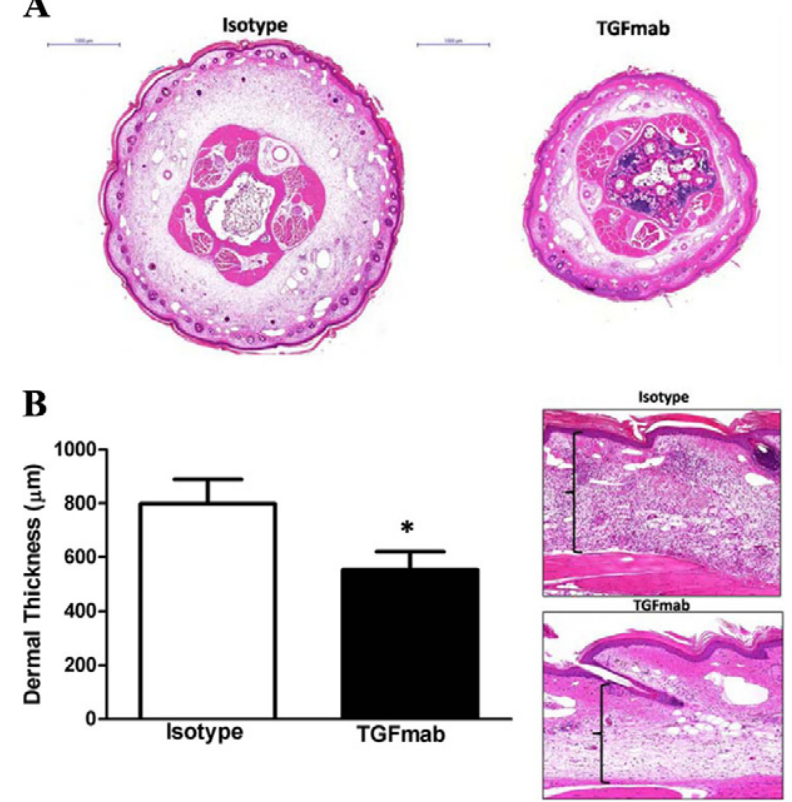

C
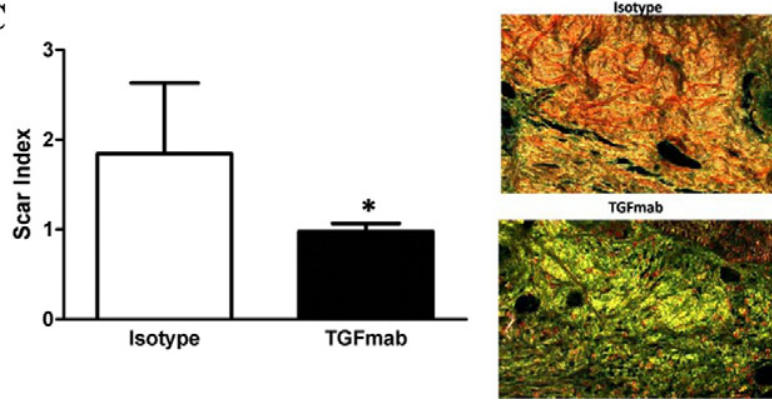

Figure 3. Systemic TGF- $\beta 1$ blockade decreases tissue fibrosis secondary to lymphatic fluid stasis. A: Representative cross-sectional histology of isotype(left) and TGFmab-treated animals 6 weeks after surgery. Twofold magnification of both sections is shown. Note marked increase in ECM deposition, hypercellularity, and dilated lymphatics in isotype-treated animals. B: Dermal thickness measurement in isotype- and TGFmab-treated animals (mean \pm SD; $\left.{ }^{*} P<0.001\right)$. Representative figures of high-power $(20 \times)$ views of longitudinal sections from isotype- (top) and TGFmab- (bottom) treated animals. C: Scar index calculation in isotype- and TGFmab-treated animals in tissues distal to the zone of lymphatic obstruction harvested 6 weeks after surgery (mean $\pm \mathrm{SD} ;{ }^{*} P<0.01$ ). Representative $20 \times$ micrographs demonstrate a predominantly red/orange birefringence (consistent with increased fibrosis) in isotype-treated animals (top). In contrast, TGFmab-treated animals demonstrate primarily a yellow/green birefringence, indicating normal ECM deposition.

of isotype treated animals. In contrast, animals treated with TGFmab had significantly decreased numbers of $\mathrm{CD}^{+}$ cells in this region of the tail (more than twofold decrease; $P<0.0001$; Figure 4B).

Th2 cells have been implicated in the regulation of tissue fibrosis in a large number of fibroproliferative disorders. Therefore, to determine the effect of TGF- $\beta$ blockade on Th1 and Th2 inflammatory responses, we localized putative Th1 cells by co-localizing CD4 and IFN- $\gamma$. Similarly, we identified putative Th2 cells by co-localizing CD4 and IL-13. This analysis demonstrated that treatment with TGFmab significantly decreased the number of Th1 cells present in the lymphedematous portion of the tail (nearly twofold; $P<0.001$; Figure $4 \mathrm{C}$ ). More importantly, we found that treatment with TGFmab resulted in a 
$\mathbf{A}$

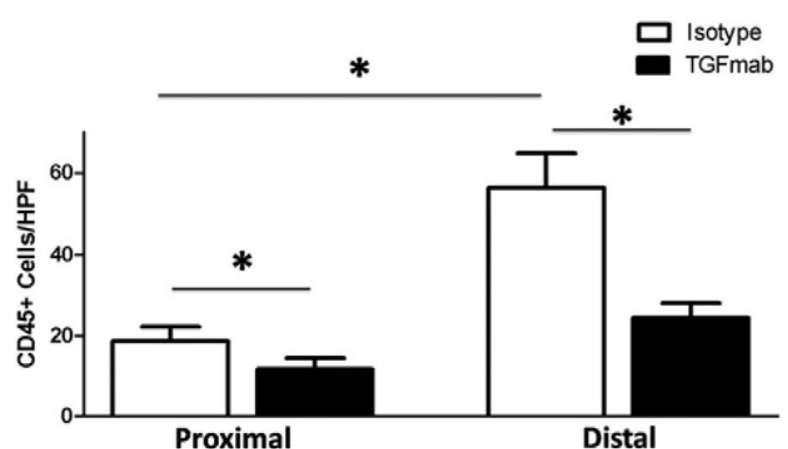

Proximal

B

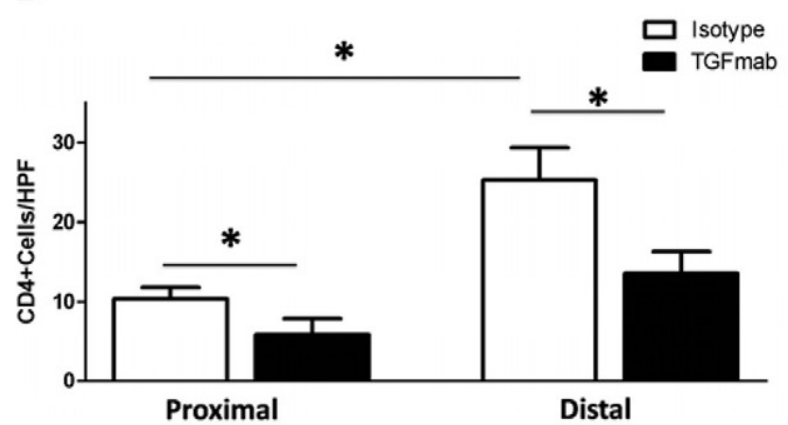

C

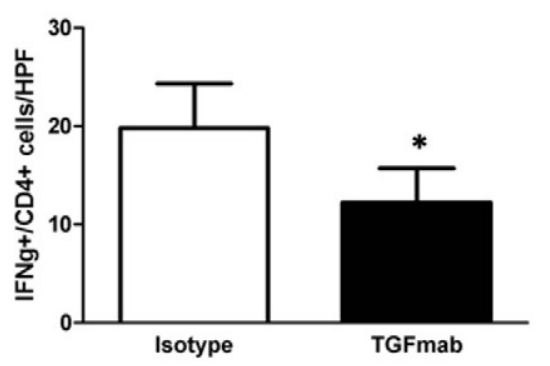

D

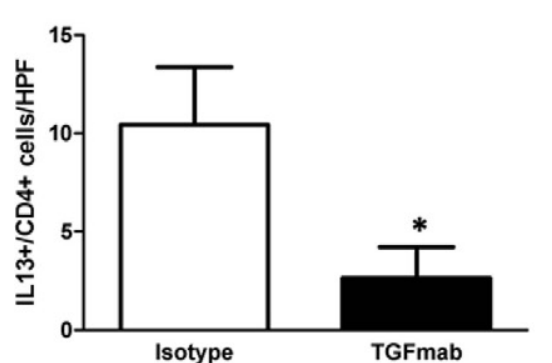

Isotype
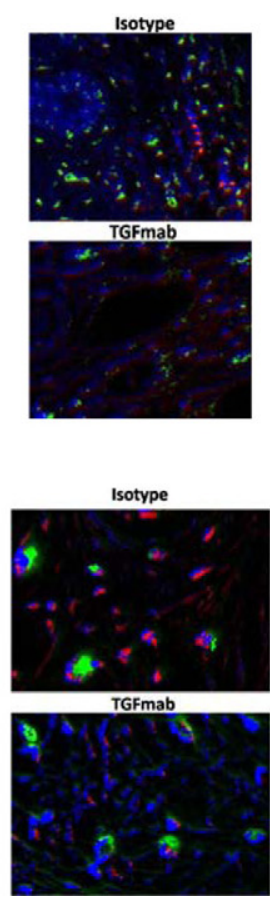

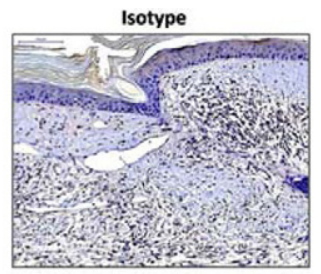

TGFmab

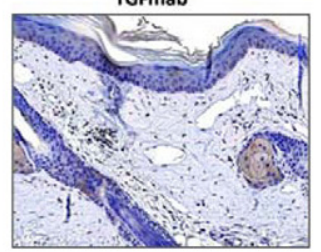

Isotype

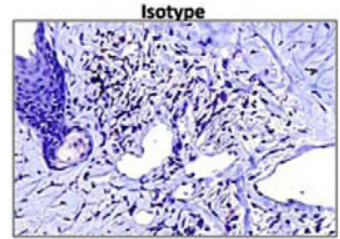

TGFmab

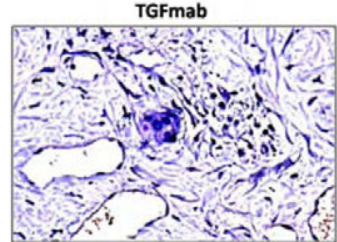

Figure 4. Systemic TGF- $\beta 1$ blockade reduces lymphedema induced chronic inflammation. A: Quantification of the number of $\mathrm{CD} 45^{+}$leukocytes/HPF in tissues located proximal or distal to the zone of lymphatic obstruction in isotype(white bars) or TGFmab-treated animals (black bars; mean $\pm \mathrm{SD} ;{ }^{*} P<0.001$ ). Representative $20 \times$ micrographs are shown to the right. B: Quantification of $\mathrm{CD}^{+}{ }^{+}$cells/HPF in tissues located proximal or distal to the zone of lymphatic obstruction in isotype- (white bars) or TGFmab-treated animals (black bars; mean $\pm \mathrm{SD} ;{ }^{*} P<0.001$ ). Representative $20 \times$ micrographs are shown to the right. Note gradients of inflammation with more $\mathrm{CD}^{+}$ cells present distal to the zone of obstruction and reduction in cell number resulting from TGFmab treatment. $\mathbf{C}$ and $\mathbf{D}$ : Quantification of presumptive Th1 (IFN- $\left.\gamma^{+} / \mathrm{CD}^{+}\right)$and Th2 (IL- $\left.13^{+} / \mathrm{CD} 4^{+}\right)$cells in TGFmab- or isotype-treated animals 6 weeks after tail excision (mean $\pm \mathrm{SD} ;{ }^{*} P<0.001$ ). $\mathbf{E}$ Representative Western blot analysis of tail soft tissues localized distal to the zone of lymphatic obstruction 6 weeks after surgery. Treatment with TGFmab resulted in marked reductions in expression of CD4, IL-4, IL-13, and TGF- $\beta 1$. In contrast, only modest differences were noted in the expression of F4/80, VEGF-C, or VEGF-A. All experiments were performed in duplicate. F: Representative Western blot analysis of tissues located distal to the zone of lymphatic obstruction in isotype- or CD3-depleted mice. Again, note decreased expression of CD4, IL- 4 , IL-13, and TGF- $\beta 1$. All experiments were performed in duplicate.

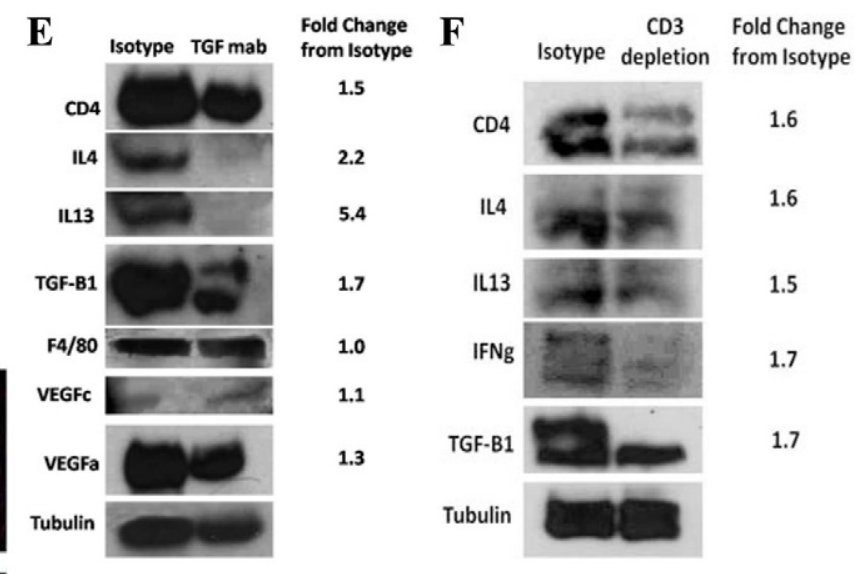

near complete loss of Th2 response as compared with isotype controls (nearly a fivefold decrease; $P<0.001$; Figure 4D).

Our immunohistochemical findings were confirmed by Western blot analysis of lymphedematous portions of the tail demonstrating marked decreases in the expression of not only TGF- $\beta 1$, but also CD4, IL- 4 , and IL-13 (Figure 4E). Interestingly, local levels of F4/80, a macrophage antigen, were unchanged by 6 weeks of TGFmab treatment suggesting that the effects of 
TGF- $\beta$ blockade on inflammatory changes is specific to chronic T-cell inflammatory reactions. Similarly, we did not find significant differences in the expression of VEGF-C at the 6-week time point suggesting that the effects of TGF- $\beta$ blockade act independently from VEGF-C. This hypothesis is supported by our previous studies demonstrating that the anti-lymphangiogenic effects of TGF- $\beta 1$ did not rely on alterations of VEGF-C expression. Finally, consistent with our finding that TGF- $\beta$ blockade caused a mild decrease in microvascular blood vessels, we found a moderate reduction of VEGF-A expression in tissues harvested from animals treated with TGFmab.

In light of the association between TGF- $\beta 1$ expression and chronic T-cell infiltration, we sought to determine if T-cells contributed to local TGF- $\beta 1$ expression. We did this by performing our surgical model and depleting T-cells by using monoclonal CD3 antibody. T-cell depletion was confirmed by flow cytometric analysis of splenocytes from treated and control animals demonstrating a near complete loss of $\mathrm{CD}^{+}$cells by Fluorescence Activated Cell Sorting (FACS) analysis (not shown). Interestingly, CD3 depletion resulted in marked reduction of local TGF- $\beta 1$ expression (Figure $4 \mathrm{~F})$. Additionally, we noted marked reductions in the expression of CD4 antigen as well as Th2 cytokines IL-4 and IL-13. In contrast, we found only minimal differences in the expression of the Th1 cytokine IFN- $\gamma$. Taken together, these findings suggest a complex interplay between local TGF- $\beta$ expression and T-cell inflammatory reactions such that each process can potentiate the other leading to a Th2-biased inflammatory reaction.

\section{Local Delivery of a Dominant Negative}

Adenovirus Expressing a Soluble, Defective Type II TGF- $\beta$ Receptor Is Efficient and

\section{Markedly Decreases Local TGF- $\beta$ Function}

Similar to our previous studies using recombinant adenoviruses, we found high levels of tissue transfection with virtually every cell infected when analyzed by gross and immunohistochemical localization of $\beta$-galactosidase in Ad-Lac-Z treated mice 1 week after surgery (Figure 5, A and $B) .{ }^{55}$ Transfection with Ad-DNRII resulted in a significant decrease in the number of phosphorylated Smad3 (PSmad3) cells as compared with no virus and Ad-Lac-Z controls (Figure 5C; $P<0.001$ ). Importantly, there was no difference in the number of $\mathrm{pSmad} 3$ positive cells when comparing no virus and Ad-Lac-Z transfected tissues. As expected, delivery of recombinant TGF- $\beta 1$ resulted in a significant increase in the number of pSmad3 positive cells. When tissues were examined 6 weeks after surgery, animals treated with Ad-DNRII continued to have fewer pSmad3 positive cells as compared with controls; however, this difference was not statistically significant. This finding is not surprising given our previous studies demonstrating that adenoviral transfer results in significant gene transfection for approximately 2 weeks (Figure 5D). ${ }^{55}$ Interestingly, and consistent with the known auto- regulatory mechanisms regulating TGF- $\beta 1$ expression, animals treated with recombinant TGF- $\beta 1$ continued to have significantly increased numbers of $\mathrm{pSmad} 3$ positive cells even 6 weeks after surgery. ${ }^{56}$

\section{Local Blockade of TGF- $\beta 1$ Activity Improves Lymphatic Function and Reduces Fibrosis}

Consistent with our previous reports, delivery of exogenous TGF- $\beta 1$ to the wound resulted in significantly increased tail lymphedema at all time points examined (Figure 6A). ${ }^{11}$ Comparison of the groups after 1 week did not demonstrate significant changes in tail volume measurements suggesting that changes in local TGF- $\beta$ function do not have significant effects on early tissue edema. However, beginning at the 2-week time point and continuing to the 6-week postoperative time period, animals treated with Ad-DNRII demonstrated significantly decreased (two- to threefold) tail volumes as compared with Ad-Lac-Z or no virus treated mice $(P<0.001)$. Decreased tail volumes in Ad-DNRII animals was associated with improved lymphatic transport as assessed by lymphoscintigraphy demonstrating significant differences in maximal decay adjusted nodal uptake between the TGF- $\beta 1$ and dominant negative groups (1.3\% vs $3.4 \%, P<0.01$; Figure 6B). Although the Ad-DNRII treated animals had a nearly $35 \%$ increase in nodal uptake as compared with no virus or Ad-Lac-Z controls, this difference did not achieve statistical significance.

Consistent with our systemic blockade of TGF- $\beta$, we found that local inhibition of TGF- $\beta$ with Ad-DNRII resulted in significant increases in the number of lymphatic vessels distal to the zone of lymphatic occlusion (nearly a $50 \%$ increase as compared with no virus or Ad-Lac-Z controls; $P<0.05$; Figure $6, C$ and $D$ ). In contrast, treatment with recombinant TGF- $\beta 1$ resulted in marked reductions in the number of lymphatic vessels in this area. These findings are likely not a virus specific effect since we found no statistically significant differences between the no-virus and Ad-Lac-Z controls.

Histological analysis of cross-sections of the tails demonstrated decreased tissue swelling and ECM deposition in Ad-DNRII treated animals as compared with no-virus and Ad-Lac-Z treated animals (Figure 6D). These findings were confirmed by dermal thickness measurements demonstrating a more than $30 \%$ decrease in Ad-DNRII treated animals as compared with no-virus treated mice (Figure 6E; $P<0.05$ ). In fact, the dermal thickness of Ad-DNRII treated animals was similar to normal, unoperated mice (not shown). Again, we found no significant differences between no-virus and Ad-Lac-Z groups, but we did find a significant increase in dermal thickness in mice treated with recombinant TGF- $\beta 1$.

Analysis of fibrosis by the scar index demonstrated significantly increased scarring in animals treated with recombinant TGF- $\beta 1$ (Figure 6F; $P<0.001$ as compared with all other groups). However, we did not find significant differences between the no-virus and Ad-Lac-Z groups as compared with Ad-DNRII treated animals. This finding may be due to the fact that the application of 
A

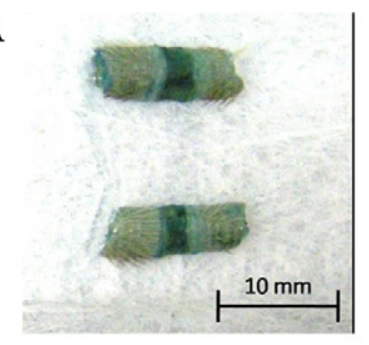

C

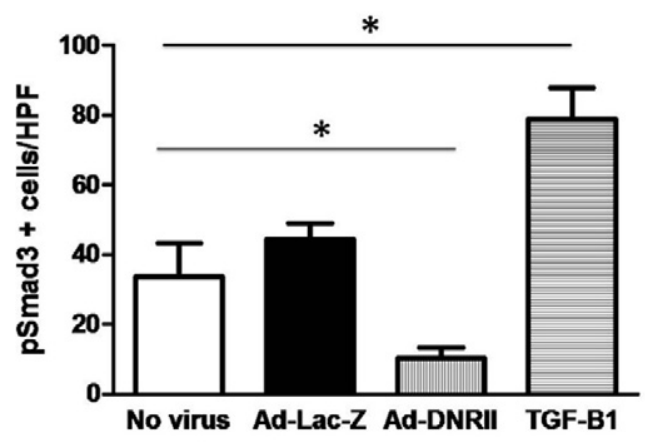

D

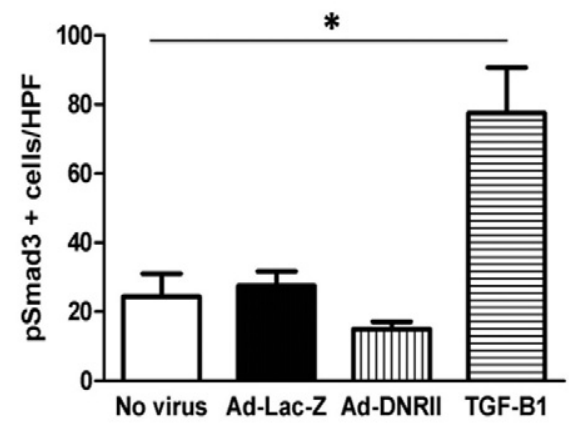

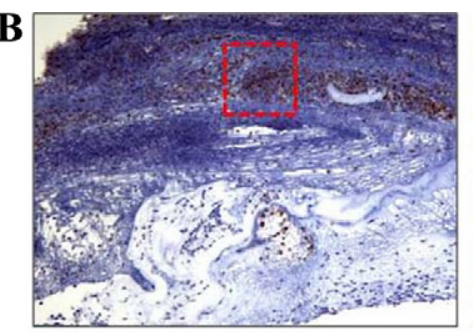

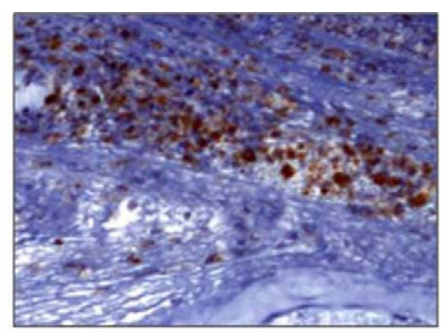

No Virus
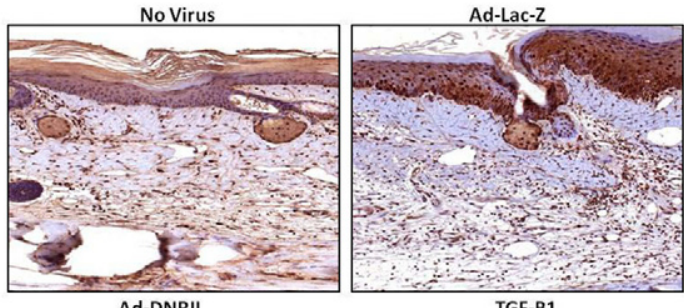

Ad-DNRII
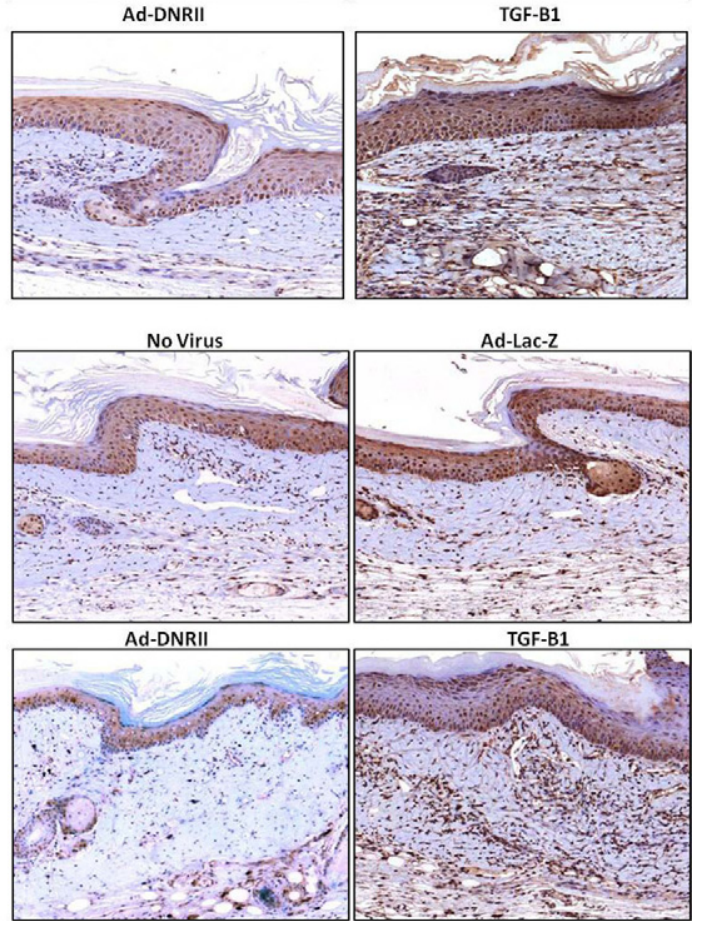

Figure 5. Adenoviruses can promote high-level transgene expression in mouse tail wound. A: A portion of tail transfected with Ad-Lac-Z was stained for $\beta$-galactosidase activity 1 week after surgery and transfect. The intense bluish staining, particularly at the wound, indicates increased activity and effective transfection. B: Immunohistochemistry for $\beta$-galactosidase demonstrated extensive expression in the peri-wound region 1 week after surgery and transfection with LacZ adenovirus. (Red Box: region of intense staining is magnified) $\mathbf{C}$ and $\mathbf{D}$ : Quantification of pSmad3 ${ }^{+}$cells/HPF in nonvirus, Ad-Lac-Z, Ad-DNRII, and recombinant TGF- $\beta 1$ treated animals 1 (C) and 6 (D) weeks after surgery/transfection. Representative $40 \times$ images are shown to the right. Note significant decrease in the number of $\mathrm{pSmad} 3^{+}$cells/HPF in Ad-DNRII treated animals 1 week after surgery (mean $\pm \mathrm{SD} ;{ }^{*} P<0.001$ ). By 6 weeks, the only significant difference among groups was the number of PSmad-3 positive cells in the recombinant TGF- $\beta 1$ treated group; ${ }^{*} P<0.001$.

collagen gel dressings significantly decreases scarring in this model and is associated with diminished TGF- $\beta 1$ expression. ${ }^{11}$ Thus, it may be difficult to demonstrate significantly decreased scarring in a situation where scarring is already diminished.

\section{Discussion}

Fibrotic disorders are among the most common causes of human disease and affect virtually every organ system. ${ }^{16}$ It is estimated that nearly 45 million people die annually as a result of complications arising from fibro- proliferative disorders. ${ }^{57}$ These disorders often result from chronic injury or irritation, and, similar to lymphedema, are characterized by chronic inflammation and replacement of functional tissue parenchyma by scar. ${ }^{16} \mathrm{We}$ have hypothesized that sustained lymphatic fluid stasis acts as a chronic irritant leading to immune dysfunction and eventual tissue fibrosis. Progressive tissue fibrosis and lymphatic dysfunction, together with the loss of the deep collecting system resulting from surgical disruption, eventually result in the development of clinically apparent lymphedema. This hypothesis is supported by the finding that experimental lymphedema promotes the coordi- 
A

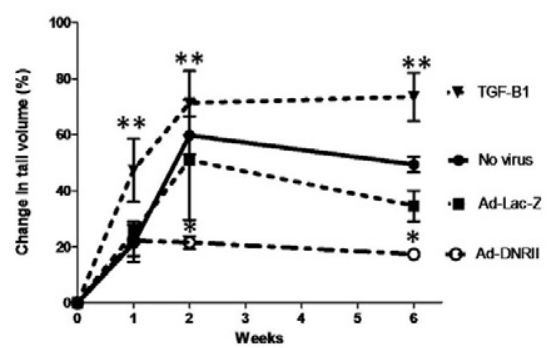

C

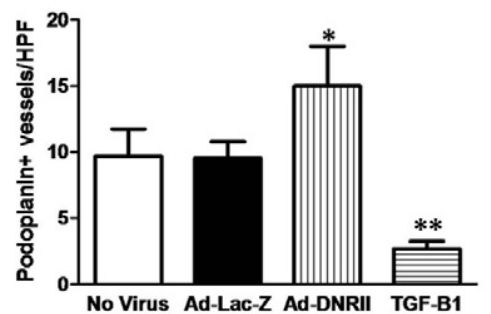

B
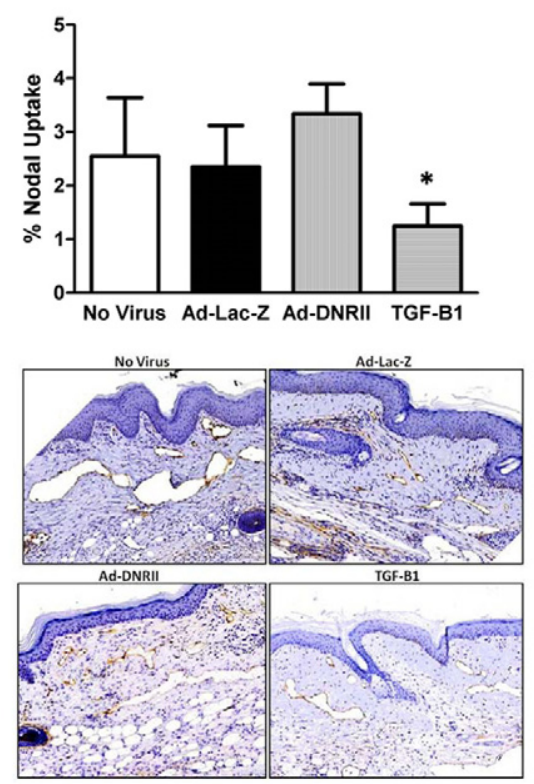

D

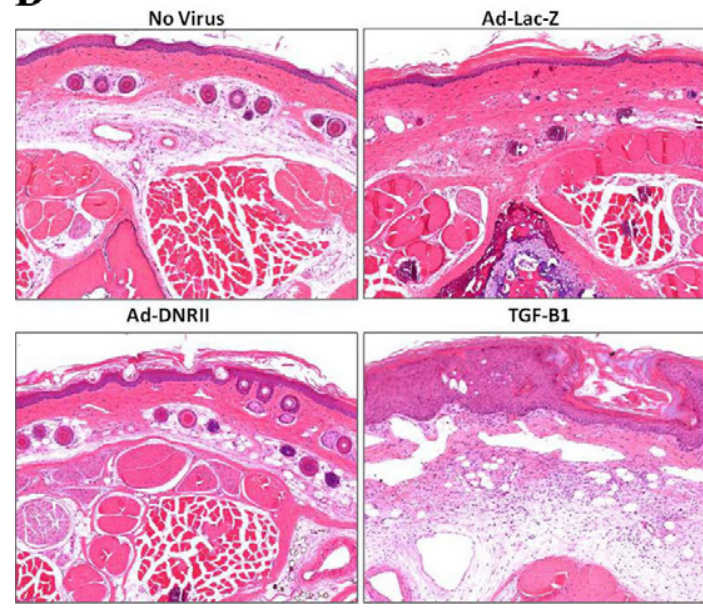

$\mathbf{E}$

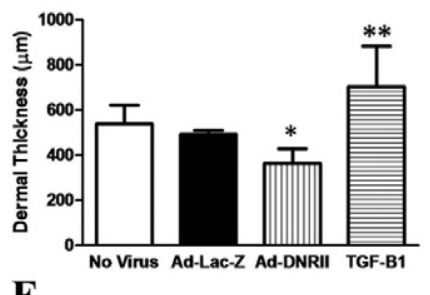

$\mathbf{F}$

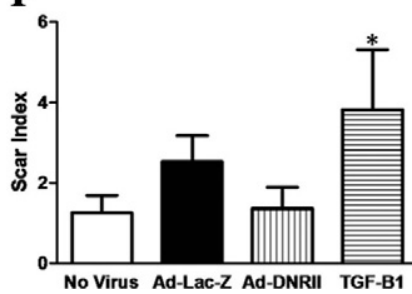

Figure 6. Local blockade of TGF- $\beta 1$ activity decreases tail edema, increases lymphangiogenesis, and decreases tissue fibrosis. A: Tail volume measurements in nonvirus, Ad-Lac-Z, Ad-DNRII, and recombinant TGF- $\beta 1$ treated animals at various time points after surgery (mean $\pm \mathrm{SD} ;{ }^{* *} P<$ 0.01). B: Lymphoscintigraphy with $\mathrm{Tc}^{99}$ demonstrated modest, though nonsignificant, increase in nodal uptake in Ad-DNRII-treated animals. In contrasts, animals treated with recombinant TGF- $\beta 1$ demonstrated markedly decreased lymphatic uptake (mean $\left.\pm \mathrm{SEM} ;{ }^{*} P<0.001\right)$. C Quantification of the number of podoplanin ${ }^{+}$ lymphatic vessels in the various experimental groups 6 weeks after surgery. Mean $\pm \mathrm{SD} ;{ }^{*} P<$ $0.002 ;{ }^{* *} P<0.001$. Representative $20 \times$ micrographs are shown to the right. D: Histological analysis of cross-sections of the tails demonstrating decreased ECM deposition and cellularity in Ad-DNRII-treated animals as compared with other groups. Representative $20 \times$ micrographs are shown. TGF-treated animals had greater swelling and lymphatic dilation compared with all other groups; $20 \times$ micrographs are presented. E: Quantitation of dermal thickness in distal tail sections 6 weeks after surgery. Treatment with Ad-DNRII decreased dermal thickness as compared with other groups. Mean \pm SD ${ }^{*} P<0.05$. Treatment with recombinant TGF- $\beta 1$ markedly increased dermal thickening; ${ }^{* *} P<$ 0.001. F: Quantitation of scar index by using Sirius red staining and computerized polarized light microscopy. Treatment with recombinant TGF- $\beta 1$ significantly increased fibrosis; ${ }^{*} P<$ 0.001 . No significant differences were noted in the other groups. nated expression of pro-inflammatory and profibrotic molecules as well as our previous studies demonstrating that sustained by not transient lymphatic fluid stasis promotes significant tissue fibrosis. ${ }^{10,58}$ Furthermore, anatomical studies of patients with lymphedema have consistently demonstrated evidence of lymphatic and soft tissue fibrosis particularly in the areas of the extremity with the greatest degree of lymphatic fluid stasis. ${ }^{59,60}$ The fibrosis theory of lymphatic dysfunction provides a rationale for the fact that postsurgical lymphedema usually occurs in a delayed fashion often 1 to 5 years after the initial surgical insult since lymphatic dysfunction resulting from tissue fibrosis would take time to develop and reach a critical threshold. This concept is additionally supported by the fact that clinical risk factors for lymphedema such as radiation, obesity, or infection either directly or indirectly increase the potential for fibrosis and that inhibition of this process experimentally markedly improves lymphatic transport function. ${ }^{7,9}$
TGF- $\beta$ is a highly conserved member of the TGF superfamily. There are three known isoforms of this molecule of which TGF- $\beta 1$ and TGF- $\beta 2$ have been implicated in the regulation of fibrosis. A large number of clinical and laboratory studies have implicated TGF- $\beta 1$ in the regulation of fibrosis in various organ systems. Indeed, TGF- $\beta 1$ is a well recognized regulator of extracellular matrix synthesis and is consistent with our finding that TGF- $\beta 1$ expression is markedly increased in tissue samples harvested from the lymphedematous limb as compared with the normal limb of patients with postsurgical lymphedema. ${ }^{22}$ Inhibition of TGF- $\beta$ function decreases fibrosis in virtually every organ system. ${ }^{25-43}$ More recently, we have shown that inhibition of radiation induced tissue fibrosis by blocking TGF- $\beta$ function markedly improves lymphatic transport function. ${ }^{12}$ These studies support our current findings that inhibition of TGF- $\beta$ function significantly decreases tissue fibrosis resulting from lymphatic fluid stasis and is associated with more rapid lymphatic 
regeneration and markedly improved lymphatic function. The use of anti-fibrotic strategies may therefore represent a means of preventing the development of lymphedema by preventing the initiation of secondary tissue changes (ie, fibrosis) that further decrease lymphatic transport function.

TGF- $\beta$ expression has been shown to be intimately associated with inflammation and to be produced by a variety of inflammatory cells. ${ }^{16,61}$ In addition, TGF- $\beta$ has important regulatory roles in T-cell differentiation and development. ${ }^{62}$ In the setting of tissue fibrosis, TGF- $\beta$ expression has been associated with chronic T-cell inflammation. ${ }^{63}$ Our finding that inhibition of TGF- $\beta$ function decreases the expression of Th2 cytokines (IL-4 and $\mathrm{IL}-13$ ) and markedly decreases not only the overall number of inflammatory cells $\left(\mathrm{CD} 45^{+}\right)$, but particularly Th2 cells is consistent with these studies. Furthermore, we found that the interaction between TGF- $\beta$ and T-cell inflammatory reactions is bi-directional as depletion of $\mathrm{CD}^{+}$cells markedly decreased the expression of TGF$\beta 1$. These findings are further supported by our previous studies demonstrating that inhibition of Th2 differentiation using an IL-4 monoclonal antibody markedly decreased tissue expression of TGF- $\beta$ with resultant decrease in fibrosis (T. Avraham unpublished data). Taken together, these findings demonstrate that TGF- $\beta$ and Th2 cytokines act in concert to regulate tissue fibrosis secondary to lymphatic fluid stasis. Similar mechanisms are thought to contribute to tissue fibrosis resulting in a number of other organ systems. For example, recent studies using IL-13 transgenic mice in which TGF- $\beta 1$ activity was inhibited have shown that subepithelial lung fibrosis resulting from Th2 polarized responses and increased IL-13 expression result as a consequence of IL-13 induction of TGF- $\beta 1$ by tissue macrophages as well as by promoting expression of matrix metalloproteinases that cleave the latency associated peptide component of TGF- $\beta 1 .{ }^{44}$ Other studies have shown that radiation induced tissue fibrosis occurs as a consequence of interactions between IL-4 and TGF- $\beta$ expression. ${ }^{16}$ Thus, it is clear that the mechanisms governing tissue fibrosis in response to lymphedema are complex and require addition study.

In the current study we noted that inhibition of TGF- $\beta$ function not only decreased fibrosis but also resulted in lymphangiogenesis as evidenced by increased numbers of lymphatic vessels. Interestingly, this effect was not associated with marked alterations in the expression of lymphangiogenic cytokines including VEGF-A, VEGF-C, and hepatocyte growth factor. These findings are consistent with our previous study demonstrating that TGF- $\beta$ can directly impair lymphatic endothelial cell proliferation and tubule formation but does alter the expression of VEGF-C. ${ }^{11}$ In addition, Oka et al ${ }^{45}$ have shown that TGF- $\beta$ impairs inflammatory lymphangiogenesis and down-regulates expression of lymphatic markers such as LYVE-1. These findings demonstrate that inhibition of lymphatic function resulting from increased expression of TGF- $\beta$ result not only from fibrosis but also from direct effects of TGF- $\beta 1$ on lymphatic vessels. In addition, these findings have important clinical implications in patients with cancer, since we show that it is possible to improve lym- phatic function without delivering lymphangiogenic cytokines. The use of lymphangiogenic cytokines in this setting may potentially increase the incidence of tumor recurrence or lymphatic metastasis since overexpression of these factors has been shown to be associated with poor prognosis and increased metastatic potential in a variety of cancer types.

Prolonged systemic inhibition of TGF- $\beta 1$ has been associated with immune deficiency and other potential toxicities. ${ }^{64}$ Therefore, the finding that either systemic or local inhibition of TGF- $\beta$ function significantly improves lymphatic regeneration, decreases fibrosis, and increases lymphatic function. Furthermore, these improvements can be seen even with a short course of treatment since adenoviral gene delivery typically promotes transgene delivery for only a limited time in vivo. These findings are likely due to autoregulation of TGF- $\beta$ expression since it is known that TGF- $\beta$ can up-regulate its own expression in a variety of settings. ${ }^{65}$ This hypothesis is supported by our finding that application of recombinant TGF- $\beta$ to the wounds resulted in increased numbers of PSmad-3 positive cells as long as 6 weeks postoperatively. Thus, short-term inhibition of TGF- $\beta$ function may improve lymphatic regeneration and diminish fibrosis thereby avoiding the potential toxicities associated with long-term treatments.

In summary, we have shown that blockade of TGF- $\beta$ results in improved lymphatic regeneration and function following surgical lymphatic ablation. These findings are associated with inhibition of $\mathrm{T}$ cell responses, and specifically a shift away from a Th2 response. The fact that TGF- $\beta$ levels are elevated in clinical samples of lymphedema suggests that our animal model accurately reflects the physiological findings associated with lymphedema. Therefore, inhibition of fibrotic mechanisms in general, or TGF- $\beta$ function in particular may represent a novel means of preventing lymphedema clinically.

\section{References}

1. Velanovich V, Szymanski W: Quality of life of breast cancer patients with lymphedema. Am J Surg 1999, 177:184-187; discussion 188

2. Beaulac SM, McNair LA, Scott TE, LaMorte WW, Kavanah MT: Lymphedema and quality of life in survivors of early-stage breast cancer. Arch Surg 2002, 137:1253-1257

3. Purushotham AD, Upponi S, Klevesath MB, Bobrow L, Millar K, Myles JP, Duffy SW: Morbidity after sentinel lymph node biopsy in primary breast cancer: results from a randomized controlled trial. J Clin Oncol 2005, 23:4312-4321

4. Tsai RJ, Dennis LK, Lynch CF, Snetselaar LG, Zamba GK, ScottConner C: The risk of developing arm lymphedema among breast cancer survivors: a meta-analysis of treatment factors. Ann Surg Oncol 2009, 16:1959-1972

5. Koul R, Dufan T, Russell C, Guenther W, Nugent Z, Sun X, Cooke AL: Efficacy of complete decongestive therapy and manual Iymphatic drainage on treatment-related lymphedema in breast cancer. Int J Radiat Oncol Biol Phys 2007, 67:841-846

6. McLaughlin SA, Wright MJ, Morris KT, Giron GL, Sampson MR Brockway JP, Hurley KE, Riedel ER, Van Zee KJ: Prevalence of lymphedema in women with breast cancer 5 years after sentine lymph node biopsy or axillary dissection: objective measurements. $\mathrm{J}$ Clin Oncol 2008, 26:5213-5219

7. Hinrichs CS, Watroba NL, Rezaishiraz H, Giese W, Hurd T, Fassl KA, 
Edge SB: Lymphedema secondary to postmastectomy radiation: incidence and risk factors. Ann Surg Oncol 2004, 11:573-580

8. Armer J, Fu MR, Wainstock JM, Zagar E, Jacobs LK: Lymphedema following breast cancer treatment, including sentinel lymph node biopsy. Lymphology 2004, 37:73-91

9. Loudon L, Petrek J: Lymphedema in women treated for breast cancer. Cancer Pract 2000, 8:65-71

10. Avraham T, Clavin NW, Daluvoy SV, Fernandez J, Soares MA, Cordeiro AP, Mehrara BJ: Fibrosis is a key inhibitor of lymphatic regeneration. Plast Reconstr Surg 2009, 124:438-450

11. Clavin NW, Avraham T, Fernandez J, Daluvoy SV, Soares MA, Chaudhry A, Mehrara BJ: TGF-beta1 is a negative regulator of lymphatic regeneration during wound repair. Am J Physiol Heart Circ Physiol 2008, 295:H2113-H2127

12. Avraham T, Yan A, Zampell J, Daluvoy S, Haimovitz-Friedman A Cordeiro A, Mehrara B: Radiation therapy causes loss of dermal lymphatic vessels and interferes with lymphatic function by TGF- $\beta 1$ mediated tissue fibrosis. Am J Physiol Cell Physiol 2010, 299: C589-C605

13. Uzarski J, Drelles MB, Gibbs SE, Ongstad EL, Goral JC, McKeown KK, Raehl AM, Roberts MA, Pytowski B, Smith MR, Goldman J: The resolution of lymphedema by interstitial flow in the mouse tail skin. Am J Physiol Heart Circ Physiol 2008, 294:H1326-H1334

14. Swartz MA, Boardman KC, Jr: The role of interstitial stress in lymphatic function and lymphangiogenesis. Ann NY Acad Sci 2002, 979:197-210; discussion 229-134

15. Rossi A, Weber E, Sacchi G, Maestrini D, Di Cintio F, Gerli R: Mechanotransduction in lymphatic endothelial cells. Lymphology 2007, 40:102-113

16. Wynn T: Cellular and molecular mechanisms of fibrosis. J Pathol 2008, 214:199-210

17. Song DJ, Min MG, Miller M, Cho JY, Yum HY, Broide DH: Toll-like receptor-9 agonist inhibits airway inflammation, remodeling and hyperreactivity in mice exposed to chronic environmental tobacco smoke and allergen. Int Arch Allergy Immunol 2010, 151:285-296

18. Mentink-Kane MM, Cheever AW, Thompson RW, Hari DM, Kabatereine NB, Vennervald BJ, Ouma JH, Mwatha JK, Jones FM, Donaldson DD, Grusby MJ, Dunne DW, Wynn TA: IL-13 receptor alpha 2 downmodulates granulomatous inflammation and prolongs host survival in schistosomiasis. Proc Natl Acad Sci USA 2004, 101:586-590

19. Chiaramonte MG, Mentink-Kane M, Jacobson BA, Cheever AW, Whitters MJ, Goad ME, Wong A, Collins M, Donaldson DD, Grusby MJ, Wynn TA: Regulation and function of the interleukin 13 receptor alpha 2 during a $T$ helper cell type 2-dominant immune response. J Exp Med 2003, 197:687-701

20. Chiaramonte MG, Donaldson DD, Cheever AW, Wynn TA: An IL-13 inhibitor blocks the development of hepatic fibrosis during a Thelper type 2-dominated inflammatory response. J Clin Invest 1999, 104:777-785

21. Cheever AW, Williams ME, Wynn TA, Finkelman FD, Seder RA, Cox TM, Hieny S, Caspar P, Sher A: Anti-IL-4 treatment of Schistosoma mansoni-infected mice inhibits development of $T$ cells and non- $B$, non-T cells expressing Th2 cytokines while decreasing egg-induced hepatic fibrosis. J Immunol 1994, 153:753-759

22. Massague J, Cheifetz S, Laiho M, Ralph DA, Weis FM, Zentella A: Transforming growth factor-beta. Cancer Surv 1992, 12:81-103

23. Flanders KC, Sullivan CD, Fujii M, Sowers A, Anzano MA, Arabshahi A, Major C, Deng C, Russo A, Mitchell JB, Roberts AB: Mice lacking $S m a d 3$ are protected against cutaneous injury induced by ionizing radiation. Am J Pathol 2002, 160:1057-1068

24. Xavier S, Piek E, Fujii M, Javelaud D, Mauvie A, Flanders K, Samuni A, Felici A, Reiss M, Yarkoni S, Sowers A, Mitchell J, Roberts A, Russo A: Amelioration of radiation-induced fibrosis inhibition of transforming growth factor-B signaling by halofunginone. J Biol Chem 2004, 279:15167-15176

25. Bonniaud P, Kolb M, Galt T, Robertson J, Robbins C, Stampfli M, Lavery C, Margetts PJ, Roberts AB, Gauldie J: Smad3 null mice develop airspace enlargement and are resistant to TGF-beta-mediated pulmonary fibrosis. J Immunol 2004, 173:2099-2108

26. Fujimoto M, Maezawa Y, Yokote K, Joh K, Kobayashi K, Kawamura H, Nishimura M, Roberts AB, Saito Y, Mori S: Mice lacking Smad3 are protected against streptozotocin-induced diabetic glomerulopathy. Biochem Biophys Res Commun 2003, 305:1002-1007

27. Sato M, Muragaki Y, Saika S, Roberts AB, Ooshima A: Targeted disruption of TGF-beta1/Smad3 signaling protects against renal tubulointerstitial fibrosis induced by unilateral ureteral obstruction. J Clin Invest 2003, 112:1486-1494

28. Stramer BM, Austin JS, Roberts AB, Fini ME: Selective reduction of fibrotic markers in repairing corneas of mice deficient in Smad3. J Cell Physiol 2005, 203:226-232

29. Badalamente MA, Sampson SP, Hurst LC, Dowd A, Miyasaka K: The role of transforming growth factor beta in Dupuytren's disease. J Hand Surg Am 1996, 21:210-215

30. Border WA, Okuda S, Languino LR, Sporn MB, Ruoslahti E: Suppression of experimental glomerulonephritis by antiserum against transforming growth factor beta 1. Nature 1990, 346:371-374

31. Isaka Y, Fujiwara Y, Ueda N, Kaneda Y, Kamada T, Imai E: Glomerulosclerosis induced by in vivo transfection of transforming growth factor-beta or platelet-derived growth factor gene into the rat kidney. J Clin Invest 1993, 92:2597-2601

32. Kawakami T, Ihn H, Xu W, Smith E, LeRoy C, Trojanowska M: Increased expression of TGF-beta receptors by scleroderma fibroblasts: evidence for contribution of autocrine TGF-beta signaling to scleroderma phenotype. J Invest Dermatol 1998, 110:47-51

33. Li RK, Li G, Mickle DA, Weisel RD, Merante F, Luss H, Rao V, Christakis GT, Williams WG: Overexpression of transforming growth factor-beta1 and insulin-like growth factor-l in patients with idiopathic hypertrophic cardiomyopathy. Circulation 1997, 96:874-881

34. Martinez OM, Villanueva JC, Gershwin ME, Krams SM: Cytokine patterns and cytotoxic mediators in primary biliary cirrhosis. Hepatology 1995, 21:113-119

35. Murawaki $Y$, Nishimura $Y$, Ikuta $Y$, Idobe $Y$, Kitamura $Y$, Kawasaki $H$ : Plasma transforming growth factor-beta 1 concentrations in patients with chronic viral hepatitis. J Gastroenterol Hepatol 1998, 13:680-684

36. Nagy P, Schaff Z, Lapis K: Immunohistochemical detection of transforming growth factor-beta 1 in fibrotic liver diseases. Hepatology 1991, 14:269-273

37. Okuda S, Languino LR, Ruoslahti E, Border WA: Elevated expression of transforming growth factor-beta and proteoglycan production in experimental glomerulonephritis: possible role in expansion of the mesangial extracellular matrix. J Clin Invest 1990, 86:453-462

38. Peltonen J, Hsiao LL, Jaakkola S, Sollberg S, Aumailley M, Timpl R, Chu ML, Uitto J: Activation of collagen gene expression in keloids: co-localization of type I and VI collagen and transforming growth factor-beta 1 mRNA. J Invest Dermatol 1991, 97:240-248

39. Qi Z, Atsuchi N, Ooshima A, Takeshita A, Ueno H: Blockade of type beta transforming growth factor signaling prevents liver fibrosis and dysfunction in the rat. Proc Natl Acad Sci USA 1999, 96:2345-2349

40. Tomita H, Egashira K, Ohara Y, Takemoto M, Koyanagi M, Katoh M, Yamamoto H, Tamaki K, Shimokawa H, Takeshita A: Early induction of transforming growth factor-beta via angiotensin II type 1 receptors contributes to cardiac fibrosis induced by long-term blockade of nitric oxide synthesis in rats. Hypertension 1998, 32:273-279

41. Van Laethem JL, Robberecht P, Resibois A, Deviere J: Transforming growth factor beta promotes development of fibrosis after repeated courses of acute pancreatitis in mice. Gastroenterology 1996, 110:576-582

42. Yoshioka K, Takemura T, Murakami K, Okada M, Hino S, Miyamoto H, Maki S: Transforming growth factor-beta protein and mRNA in glomeruli in normal and diseased human kidneys. Lab Invest 1993 68:154-163

43. Zhang HY, Gharaee-Kermani M, Zhang K, Karmiol S, Phan SH: Lung fibroblast alpha-smooth muscle actin expression and contractile phenotype in bleomycin-induced pulmonary fibrosis. Am J Pathol 1996, 148:527-537

44. Lee CG, Homer RJ, Zhu Z, Lanone S, Wang X, Koteliansky V, Shipley JM, Gotwals P, Noble P, Chen Q, Senior RM, Elias JA: Interleukin-13 induces tissue fibrosis by selectively stimulating and activating transforming growth factor beta(1). J Exp Med 2001, 194:809-821

45. Oka M, Iwata C, Suzuki HI, Kiyono K, Morishita Y, Watabe T, Komuro A, Kano MR, Miyazono K: Inhibition of endogenous TGF-\{beta\} signaling enhances lymphangiogenesis. Blood 2008, 111(9):4571-4579

46. Boardman KC, Swartz MA: Interstitial flow as a guide for lymphangiogenesis. Circ Res 2003, 92:801-808

47. Ruzek MC, Hawes M, Pratt B, McPherson J, Ledbetter S, Richards SM, Garman RD: Minimal effects on immune parameters following chronic anti-TGF-beta monoclonal antibody administration to normal mice. Immunopharmacol Immunotoxicol 2003, 25:235-257 
48. Haviv YS, Takayama K, Nagi PA, Tousson A, Cook W, Wang M, Lam JT, Naito S, Lei X, Carey DE, Curiel DT: Modulation of renal glomerular disease using remote delivery of adenoviral-encoded solubletype II TGF-beta receptor fusion molecule. J Gene Med 2003, 5:839-851

49. Alegre ML, Tso JY, Sattar HA, Smith J, Desalle F, Cole M, Bluestone JA: An anti-murine CD3 monoclonal antibody with a low affinity for Fc gamma receptors suppresses transplantation responses while minimizing acute toxicity and immunogenicity. J Immunol 1995, 155:1544-1555

50. Sitzia J: Volume measurement in lymphoedema treatment: examination of formulae. Eur J Cancer Care (Engl) 1995, 4:11-16

51. Rutkowski JM, Boardman KC, Swartz MA: Characterization of lymphangiogenesis in a model of adult skin regeneration. Am J Physiol Heart Circ Physiol 2006, 291:H1402-H1410

52. Pierard GE: Sirius red polarization method is useful to visualize the organization of connective tissues but not the molecular composition of their fibrous polymers. Matrix 1989, 9:68-71

53. Ehrlich HP, Desmouliere A, Diegelmann RF, Cohen IK, Compton CC, Garner WL, Kapanci Y, Gabbiani G: Morphological and immunochemical differences between keloid and hypertrophic scar. Am J Pathol 1994, 145:105-113

54. Mehrara BJ, Mackool RJ, McCarthy JG, Gittes GK, Longaker MT: Immunolocalization of basic fibroblast growth factor and fibroblast growth factor receptor-1 and receptor-2 in rat cranial sutures. Plast Reconstr Surg 1998, 102:1805-1817; discussion 1818-1820

55. Spector JA, Mehrara BJ, Luchs JS, Greenwald JA, Fagenholz PJ, Saadeh PB, Steinbrech DS, Longaker MT: Expression of adenovirally delivered gene products in healing osseous tissues. Ann Plast Surg 2000, 44:522-528

56. Moore LD, Isayeva T, Siegal GP, Ponnazhagan S: Silencing of transforming growth factor-beta1 in situ by RNA interference for breast cancer: implications for proliferation and migration in vitro and metastasis in vivo. Clin Cancer Res 2008, 14:4961-4970

57. Wynn TA: Common and unique mechanisms regulate fibrosis in various fibroproliferative diseases. J Clin Invest 2007, 117:524-529

58. Tabibiazar R, Cheung L, Han J, Swanson J, Beilhack A, An A, Dadras SS, Rockson N, Joshi S, Wagner R, Rockson SG: Inflammatory manifestations of experimental lymphatic insufficiency. PLoS Med 2006 3:e254

59. Suami H, Pan WR, Taylor Gl: Changes in the lymph structure of the upper limb after axillary dissection: radiographic and anatomical study in a human cadaver. Plast Reconstr Surg 2007, 120:982-991

60. Daroczy J: Pathology of lymphedema. Clin Dermatol 1995, 13:433-444

61. Nacu N, Luzina IG, Highsmith K, Lockatell V, Pochetuhen K, Cooper ZA, Gillmeister MP, Todd NW, Atamas SP: Macrophages produce TGF-beta-induced (beta-ig-h3) following ingestion of apoptotic cells and regulate MMP14 levels and collagen turnover in fibroblasts. J Immunol 2008, 180:5036-5044

62. Wolfraim LA, Fernandez TM, Mamura M, Fuller WL, Kumar R, Cole DE, Byfield S, Felici A, Flanders KC, Walz TM, Roberts AB, Aplan PD, Balis FM, Letterio JJ: Loss of Smad3 in acute T-cell Iymphoblastic leukemia. N Engl J Med 2004, 351:552-559

63. Pesce JT, Ramalingam TR, Mentink-Kane MM, Wilson MS, El Kasmi KC, Smith AM, Thompson RW, Cheever AW, Murray PJ, Wynn TA: Arginase-1-expressing macrophages suppress Th2 cytokine-driven inflammation and fibrosis. PLoS Pathog 2009, 5:e1000371

64. Prud'homme GJ: Pathobiology of transforming growth factor beta in cancer, fibrosis and immunologic disease, and therapeutic considerations. Lab Invest 2007, 87:1077-1091

65. Hanada T, Yoshimura A: Regulation of cytokine signaling and inflammation. Cytokine Growth Factor Rev 2002, 13:413-421 